\title{
Enhancing the Performances of Polymeric PVDF Membranes for Oil/Water Separation by Hydrophilic and Underwater Oleophobic Surfaces Modification
}

\author{
Faraziehan Senusi ${ }^{1,2}$, Benjamin Ballinger ${ }^{1}$, and Suzylawati Ismail ${ }^{1, *}$ \\ ${ }^{1}$ School of Chemical Engineering, Universiti Sains Malaysia, Engineering Campus, 14300 Pulau Pinang, Malaysia \\ ${ }^{2}$ Faculty of Chemical Engineering, Universiti Teknologi MARA (UiTM) Pulau Pinang, \\ Permatang Pauh 13500 Pulau Pinang, Malaysia
}

* Corresponding author:

tel: +604-5996458

email: chsuzy@usm.my

Received: February 4, 2019

Accepted: April 3, 2019

DOI: $10.22146 / \mathrm{ijc} .43314$

\begin{abstract}
This paper investigates the permeability and separation performance of polyphenolic-amine coated PVDF membrane with hydrophilic $\left(26.9 \pm 5.6^{\circ}\right)$ and underwater oleophobic $\left(162.1 \pm 5.1^{\circ}\right)$ surface modification. Surface chemical structures, surface compositions and hydrophilicity of membranes were investigated by Attenuated Total Reflectance Fourier transform infrared (ATR-FTIR) spectroscopy, X-ray photoelectron spectroscopy (XPS) and contact angle analysis, respectively. The separation of emulsion oil solutions was evaluated using cross-flow filtration mode in terms of high permeation flux and excellent oil resistance. Then, the flux recovery ratio of filtration process was calculated at different transmembrane pressures (TMP) and initial concentrations of emulsion feed solutions. The results showed a decrease in the flux recovery ratio at higher pressures and initial oil concentrations. By applying Hermia's blocking model, formation of cake layer shows dominant fouling mechanism for the emulsion oil separation process.
\end{abstract}

Keywords: polyphenolic coating; hydrophilicity; underwater oleophobic; polymeric membrane; emulsion oil

\section{- INTRODUCTION}

The separation of oily wastewater, especially for surfactant-stabilized emulsions with droplet sizes smaller than $20 \mu \mathrm{m}$ require a promising method in order to meet the requirements of high quality of the permeate flux with low operating costs [1-2]. Due to the micron sizes, emulsion droplets require a long time for effective gravity separation and ineffective breaking process, even after the addition of chemicals because of its high stability in water. Thus, the polymeric membrane filtration is one of the promising and advanced technology for the separation of various types of wastewater including emulsified oil/water mixtures.

However, the main problem for membrane separation is fouling phenomena due to the surfactant adsorption and pore blocking which can cause a severe decline of flux and rejection efficiency [3]. Generally, the fouling decreases with an increase in hydrophilicity of the membrane surface and it offers better membrane fouling resistance. In order to achieve better membrane performance, various strategies; bulk modification blending process [4-5] and the surface modification of membranes [6-8] have been applied which contributes to the enhancement in membrane performances. In addition, PVDF membranes are the most extensively used in the water treatment marketplace [9-10]. However, the performance need to be improved especially on the wettability and fouling behavior due to their hydrophobic properties [11].

To date, exciting findings have been constantly made through mussel and plant inspired chemistry using polydopamine [12] and plant (poly)phenols [13] as 'bio-glue' as well as a surface modifying agent that hydrophilize many substrates including; metals [14], glass [15] and a wide variety of polymers [16-17]. The surfaces of various substrates were improved by the existence of catechol and amine groups that have the capability to adhere on these substrates. In this study, 
tannic acid as plant polyphenol derivatives have been used to transform the surface of hydrophobic polymer to become highly hydrophilic with underwater oleophobic properties and low oil adhesion for oily wastewater treatment. The polyvinylidene fluoride (PVDF) porous membrane were modified via facile deposition method using polyphenolic-amine coating by mussel-inspired coating approach [18]. It was found that the water permeability and removal efficiency of emulsion oils were improved significantly. In addition, this paper also emphasizes on the analysis of fouling mechanism of emulsion oil solutions based on a blocking model filtration on the modified membrane.

\section{- EXPERIMENTAL SECTION}

\section{Materials}

Rolls of flat sheet polyvinylidene fluoride (PVDF) membranes $(0.22 \mu \mathrm{m}$, porosity $75 \%)$, tannic acid (TA) and tetraethylenepentamine (TEPA) were purchased from Merck Malaysia. Tris(hydroxymethyl) aminomethane and isopropanol (IPA) were supplied by Friendemann Schmidt Chemical and sodium hydroxide $(\mathrm{NaOH})$ was obtained from R\&M Chemicals. All chemicals were used as received. Diesel oil (Shell Malaysia) and Tween 80 (Friendemann Schmidt Chemical) were used in the preparation of emulsion oil as synthetic oil feed solution.

\section{Procedure}

\section{Surface modification of flat sheet membrane}

Prior to the coating process, the pristine PVDF membranes $\left(\mathrm{M}_{0}\right)$ with fixed size of $11.5 \mathrm{~cm} \times 7 \mathrm{~cm}$ were immersed in $25 \%$ of IPA for $24 \mathrm{~h}$ to wet the pores, then soaked overnight with deionized water (DI). Next, $0.2 \mathrm{~g}$ of TA and $1.2 \mathrm{~mL}$ of TEPA were dissolved in $100 \mathrm{~mL}$ of $50 \mathrm{mM}$ Tris- $\mathrm{HCl}$ buffer solution ( $\mathrm{pH} 9$ ) for $30 \mathrm{~min}$. Then, the prewetted PVDF membranes were immersed into the solution with mild shaking in open containers for $6 \mathrm{~h}$ at $30^{\circ} \mathrm{C}$. Finally, the coated membranes, labelled as $\mathrm{M}_{\mathrm{C}}$, were immersed in $25 \%$ of IPA for $30 \mathrm{~min}$ and soaked with DI water for $12 \mathrm{~h}$ to remove redundant solution and later dried in air drying oven at $45^{\circ} \mathrm{C}$. Then, the membrane surface wettability was evaluated using a Dropmeter A-200
(Rame-Hart Instrument Co., U.S.A) contact angle system by detection of water contact angles using 1,2Dichloroethane as a model oil to characterize the underwater oleophobicity. The surface chemical structure and chemical composition of the membranes were determined by attenuated total reflectance Fourier transform infrared spectra (ATR-FTIR, Thermo Scientific Nicolet iS10) and X-ray photoelectron spectroscopy (Axis Ultra DLD XPS, Kratos), respectively.

\section{Pure water permeance experiments}

The permeability of the membranes was evaluated using a laboratory scale crossflow filtration unit as shown in Fig. 1. The permeate exited at atmospheric pressure into a beaker sitting on an electronic balance (EK3000i, A\&D Company). The balance was connected to a RSWeight WinCT software supplied by $A \& D$ Company, which automatically recorded the mass of permeate flux as function of time. The effective filtration area of membrane for this study was $33.6 \mathrm{~cm}^{2}$. Prior to each filtration process, pure water was flowed through the membrane cell for 30 min under transmembrane pressures (TMP) of $0.20 \mathrm{MPa}$ to compress the membrane. Then, the permeability tests were conducted in the range of $0.05-0.20 \mathrm{MPa}$. The pure water flux, $\mathrm{J}$ (LMH) was calculated as Eq. 1 where, $\Delta \mathrm{m}$ is the mass of permeated flux for a period of operation time $(\Delta \mathrm{t}), \rho_{\mathrm{w}}$ is the density of water and $A$ is the effective filtration area. $\mathrm{J}=\frac{\Delta \mathrm{m}}{\rho_{\mathrm{w}} \mathrm{A} \Delta \mathrm{t}}$

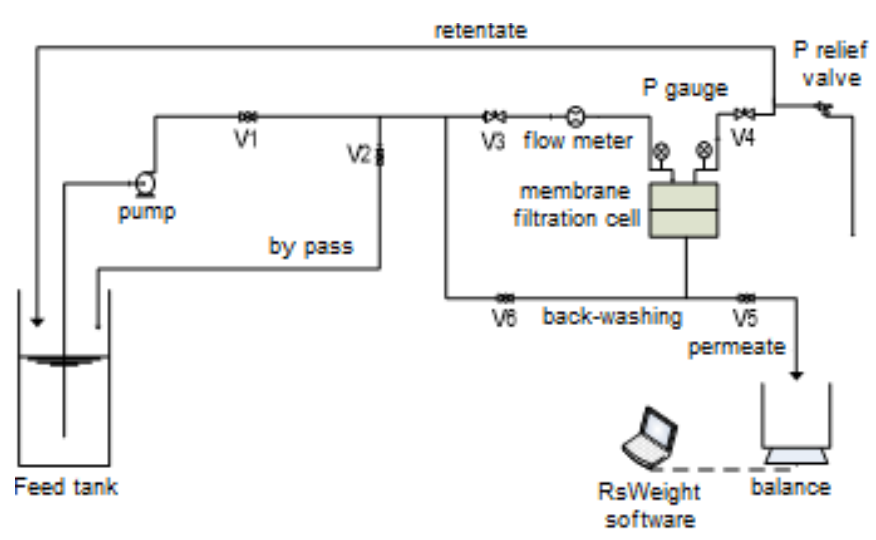

Fig 1. A laboratory scale crossflow filtration unit 


\section{Separation property and fouling studies}

The foulant employed in this study was an emulsion of diesel oil in water, in which $4.82 \mathrm{~mL}$ of diesel oil and $0.42 \mathrm{~mL}$ of Tween 80 as surfactant were blended with $3 \mathrm{~L}$ of pure water at $6000 \mathrm{rpm}$ for $30 \mathrm{~min}$ in a homogenizer (Ultra Turrax T-50, IKA). The droplet size of the emulsion was in the range of $0.20-10 \mu \mathrm{m}$ with a mean diameter of $3.6 \mu \mathrm{m}$ detected by the particle size analyzer (Cilas). The oil rejection was calculated by determining the oil concentration in the feed and permeate solution by UV spectrophotometer (DR 6000, Hach) at maximum wavelength of $198 \mathrm{~nm}$ which was observed using quartz cuvette. The relation between the absorbance and oil concentration was initially calibrated for different known oil concentrations as a linear calibration curve with $\mathrm{R}^{2}=$ 0.9948. The removal efficiency, $\mathrm{R}(\%)$ was calculated as follows:

$\mathrm{R}=\left(1-\frac{\mathrm{C}_{\mathrm{P}}}{\mathrm{C}_{\mathrm{F}}}\right) \times 100 \%$

where $\mathrm{R}(\%)$ is the oil removal percentage, $\mathrm{C}_{\mathrm{P}}$ and $\mathrm{C}_{\mathrm{F}}$ are the emulsion oil concentrations in permeate and feed, respectively.

The filtration of emulsion oil solutions at different TMP and oil concentrations were applied using the recyclable steps after the compaction of the modified membrane at $0.20 \mathrm{MPa}$ for $30 \mathrm{~min}$. The stable water flux $\left(\mathrm{J}_{\mathrm{W}}\right)$ was obtained by pure water filtration after $70 \mathrm{~min}$. Then, the feed solution was changed to emulsion oil for 100 min until the stable flux of permeate $\left(J_{P}\right)$ was obtained. The cleaning process was performed by flushing method using $0.005 \mathrm{M}$ acid solution $(\mathrm{HCl})$ without applying the hydraulic pressure for $5 \mathrm{~min}$, followed by rinsing with pure water for the next $10 \mathrm{~min}$. Finally, the feed solution was changed to pure water again to record the pure water flux $\left(\mathrm{J}_{\mathrm{C}}\right)$ after the cleaning process. The water flux recovery ratio (FRR) indicates the degree of irreversible effects of emulsion oil on the membrane surface during filtration process and was calculated by the following equation:

$\operatorname{FRR}(\%)=\frac{\mathrm{J}_{\mathrm{C}}}{\mathrm{J}_{\mathrm{W}}} \times 100$

The empirical models to describe permeate flux decline were presented by Hermia [19] based on constant pressure filtration laws that correspond to four basic types of fouling [20] as illustrated in Table 1: complete blocking (a), intermediate blocking (b), standard blocking (c) and cake layer formation (d). The characteristic form of Hermia model is given as:

$\frac{\mathrm{d}^{2} \mathrm{t}}{\mathrm{dV}^{2}}=\mathrm{k}\left(\frac{\mathrm{dt}}{\mathrm{dV}}\right)^{\mathrm{n}}$

where, $\mathrm{t}$ and $\mathrm{V}$ are the filtration time and cumulative permeate volume, respectively, and $\mathrm{k}$ and $\mathrm{n}$ are two model parameters.

\section{- RESULTS AND DISCUSSION}

\section{Permeability and Separation Performance of Modified Membrane}

The surface hydrophilicity of the pristine and modified membranes were evaluated by using pure water flux and contact angle analysis. The static water contact angle (WCA) and underwater oil contact angle (OCA) are displayed in Fig. 2(a). The pristine membrane $\left(\mathrm{M}_{0}\right)$ shows a hydrophobic nature surface with WCA of $90^{\circ}$ and exhibited a low pure water flux of $86.7 \mathrm{LMH}$, 92.2 LMH and 187.2 LMH at 0.05, 0.10 and $0.20 \mathrm{MPa}$, respectively. The hydrophilicity of the modified membrane $\left(M_{C}\right)$ had a great improvement, which was proven by the significant decrease of the WCA with the

Table 1. Blocking filtration models at constant filtration pressure

\begin{tabular}{|c|c|c|c|c|c|}
\hline Blocking Models & Equations & Schematic view & Blocking Models & Equations & Schematic view \\
\hline $\begin{array}{l}\text { Complete pore } \\
\text { blocking }(n=2)\end{array}$ & $\ln \left(\frac{1}{J}\right)=\ln \left(\frac{1}{J_{0}}\right)+k_{b} t$ & & $\begin{array}{l}\text { Intermediate pore } \\
\text { blocking }(n=1)\end{array}$ & $\frac{1}{\mathrm{~J}}=\frac{1}{\mathrm{~J}_{0}}+\mathrm{k}_{\mathrm{i}} \mathrm{t}$ & 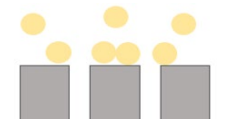 \\
\hline $\begin{array}{l}\text { Standard pore } \\
\text { blocking }(\mathrm{n}=1.5)\end{array}$ & $\frac{1}{\sqrt{\mathrm{J}}}=\frac{1}{\sqrt{\mathrm{J}_{0}}}+\mathrm{k}_{\mathrm{s}} \mathrm{t}$ & 00000000 & $\begin{array}{l}\text { Cake layer } \\
\text { formation }(n=0)\end{array}$ & $\frac{1}{\mathrm{~J}^{2}}=\frac{1}{\mathrm{~J}_{0}^{2}}+\mathrm{k}_{\mathrm{c}} \mathrm{t}$ & \\
\hline
\end{tabular}




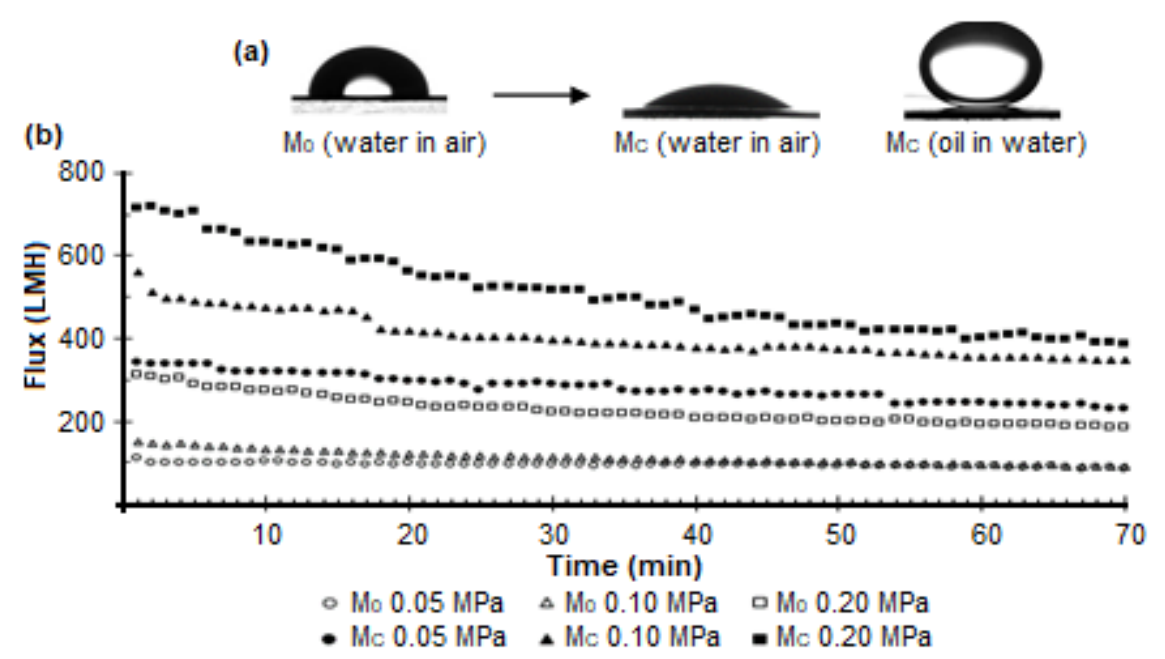

Fig 2. Contact angle in air and underwater (a) and pure water flux at different TMP (b) for membranes $M_{0}$ and $M_{C}$

modification to $26.9 \pm 5.6^{\circ}$. Moreover, the pure water flux of $\mathrm{M}_{\mathrm{C}}$ was significantly enhanced at each of the observed TMP as shown in Fig. 2(b) with the permeate flux for $0.05 \mathrm{MPa}$ reaching 237.0 $\mathrm{LMH}$. When the pressure was observed at 0.10 and $0.20 \mathrm{MPa}$, the pure water flux reached 351.8 and $398.7 \mathrm{LMH}$, respectively. The improvements on the flux are attributed to the large amount of hydrophilic hydroxyl groups on the modified $\mathrm{M}_{\mathrm{C}}$ membrane surface which leads to higher water permeation [21].

\section{(a)}
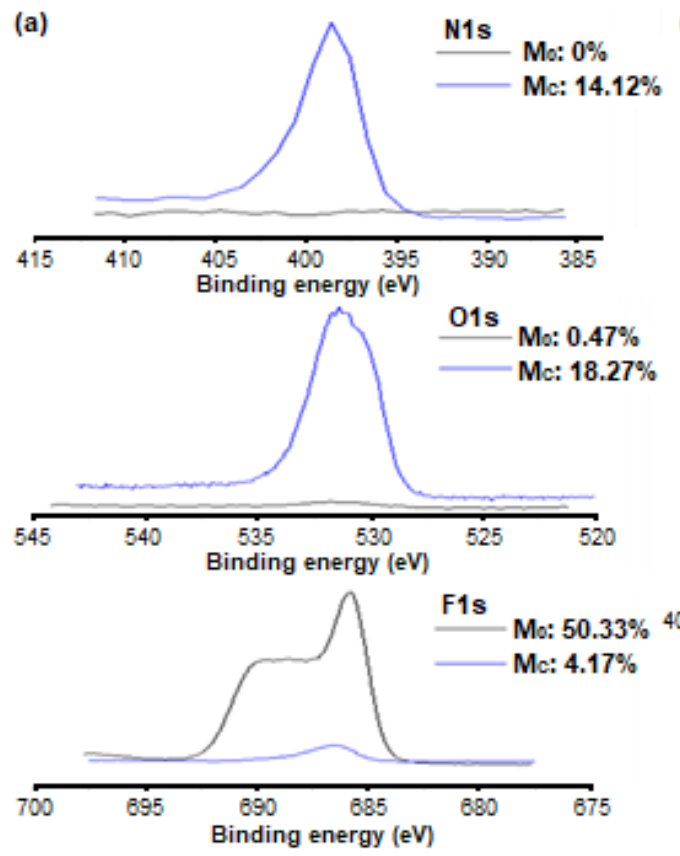

The successful coating of the membrane surfaces that change the wetting properties could be confirmed by FTIR spectra analysis as shown in Fig. 3(b). The new broad peak between 3100 and $3600 \mathrm{~cm}^{-1}$ appears for $M_{C}$ membranes which corresponded to the $\mathrm{O}-\mathrm{H}$ stretching vibration [22]. It obviously indicated the successful adsorption of hydroxyl groups of polyphenolic tannic acid on the membrane surfaces. The new peak at 1668 and $1592 \mathrm{~cm}^{-1}$ was assigned to the aromatic ring $(\mathrm{C}=\mathrm{N})$ and $\mathrm{N}-\mathrm{H}$ stretching of TEPA with polyphenolic, respectively,

(b)

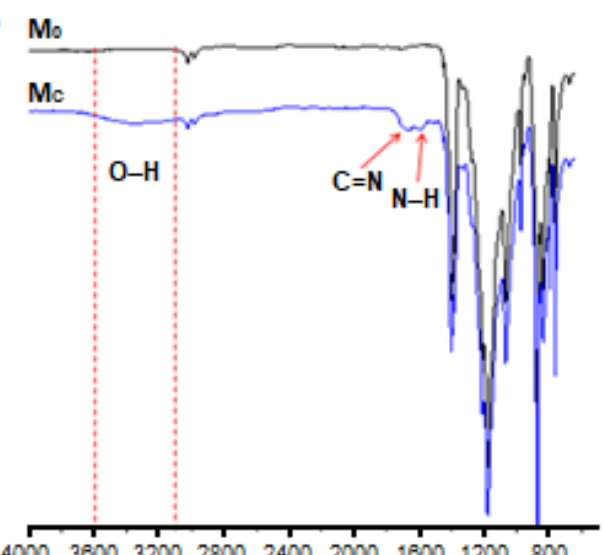

Wavelength $\left(\mathrm{cm}^{-1}\right)$

Fig 3. XPS high-resolution spectra of N1s, O1s and F1s narrow scans as a function of electron binding energy (a) and FTIR spectra (b) for membranes $\mathrm{M}_{0}$ and $\mathrm{M}_{\mathrm{C}}$ 
during the Michael addition and Schiff bases reaction [2324]. The similar results of FTIR spectra were also observed by other researchers for the hydrophilic coated membranes [25-26].

The ATR-FTIR results can also be confirmed by XPS analysis in Fig. 3(a), which showed the difference of surface composition for modified membranes, $\mathrm{M}_{\mathrm{C}}$. The new peaks of N1s and O1s elements appeared with 14.12 and $18.27 \%$ of atom percentages due to introduction of amine and $-\mathrm{OH}$ groups, respectively [27]. The peak intensities of $\mathrm{F} 1 \mathrm{~s}$ with atomic percentage decreased dramatically to $4.17 \%$ due to the defluorination of the pristine membrane, $M_{0}$ that occurred during this coating process. Sun et al. reported that the elimination of $\mathrm{F}^{-}$ occurred in the alkaline treatment for the surface modification of the PVDF membrane [28]. This concurred with the alkaline medium of polyphenolicamine coating solution that can accelerate the interaction of hydroxyl-amine groups onto the $\mathrm{M}_{\mathrm{C}}$ membrane surfaces through hydrogen bonding. Similar observation results were obtained for coated dual layer PVDF hollow fiber membranes reported by Shi et al. [29].

The hydrophilicity and underwater oleophobicity enable the modified membranes to achieve great potential in separating emulsified oil/water mixtures. The oil rejection and permeate flux were measured every $5 \mathrm{~min}$ by increasing the operation pressure from 0.025 to $0.20 \mathrm{MPa}$ with an interval of $0.02 \mathrm{MPa}$ as shown in Fig. 4. It was observed that oil removal efficiency and permeate flux were influenced by operating pressure. As concluded, when TMP rises, the rejection quickly decreased for the pristine $\mathrm{M}_{0}$ membranes, while the permeate flux was lower compared to modified $\mathrm{M}_{\mathrm{C}}$ membranes under the pressures from 0.025 to $0.06 \mathrm{MPa}$. The permeate flux start increasing from $0.08 \mathrm{MPa}$, however the separation of emulsion oil becomes worse at this state. This pressure was defined as emulsified oil critical pressure in which the suspended oil droplets on the surface would be pressed through the membranes, seriously deteriorating the separation efficiency [30].

For the modified $\mathrm{M}_{\mathrm{C}}$ membranes, the oil rejections were maintained at approximately $90 \%$ with the higher flux from $0.025 \mathrm{MPa}$ to $0.12 \mathrm{MPa}$ and then slightly decreased to $83 \%$ at pressure of $0.20 \mathrm{MPa}$ with the nearly constant flux. According to the above results, the surface wettability and low oil adhesion on the membrane surface of the modified $\mathrm{M}_{\mathrm{C}}$ membranes improved further due to the enhancement of hydrophilicity. The better oil repelling ability is useful in reducing pore blockage by oil droplets especially under low precompacting pressures. It agrees with the results of underwater oleophobicity which demonstrate low oil adhesion of the membrane surfaces with oil contact angle of $162.1 \pm 5.1^{\circ}$. The improvements on breakthrough pressure and separation efficiency was also observed by Xue et al. [31].

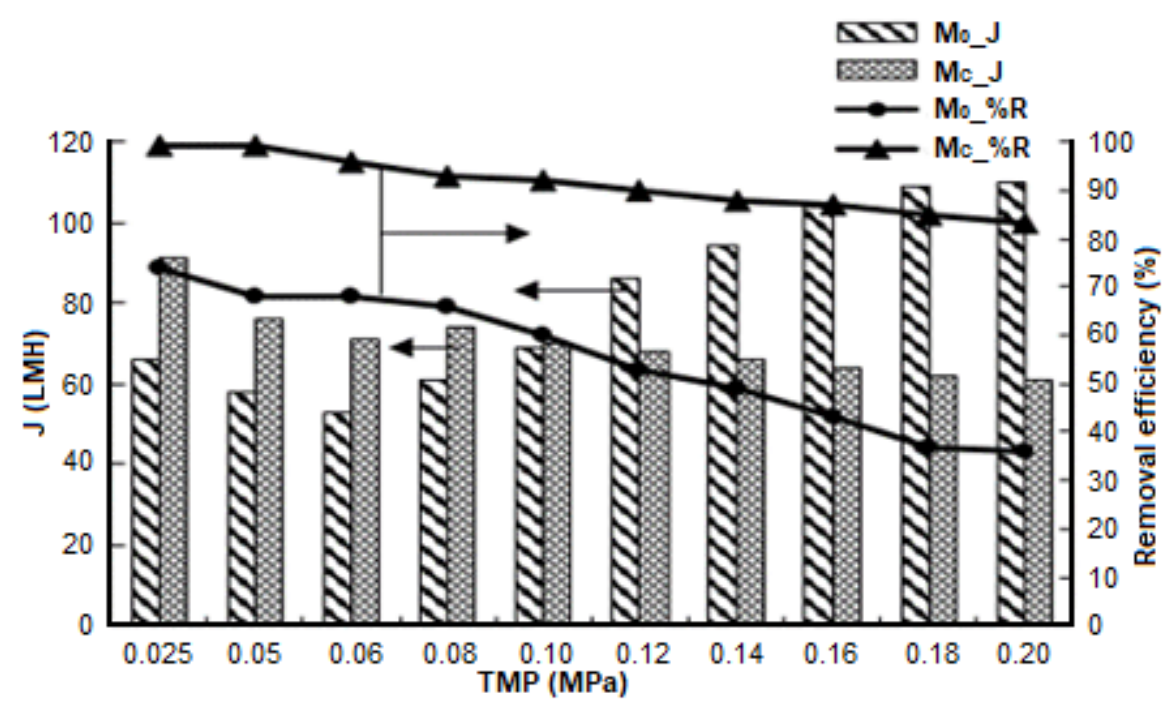

Fig 4. Permeate flux and separation efficiency of emulsion oil with increased pressure for membranes $\mathrm{M}_{0}$ and $\mathrm{M}_{\mathrm{C}}$ 


\section{Fouling Mechanism Studies}

The separation of emulsion oil at different transmembrane pressures (TMP) is presented in Fig. 5(a). As can be observed, initial flux of pure water $\left(\mathrm{J}_{\mathrm{w}}\right)$ increases with increasing TMP. Then, the steady state of permeation flux for emulsion oil $\left(\mathrm{J}_{\mathrm{p}}\right)$ are $49.4 \pm 1.6 \mathrm{LMH}$, $53.9 \pm 0.7 \mathrm{LMH}$ and $55.5 \pm 0.9 \mathrm{LMH}$, for $0.05,0.10$ and $0.20 \mathrm{MPa}$, respectively. The results show that higher TMP results in droplets passing rapidly through the membrane pores due to the increase in driving force across the membrane. However, after the membranes were cleaned, the recovery flux decreased as the TMP increased.

The flux recovery ratio (FRR) for TMP values of $0.05,0.10$ and $0.20 \mathrm{MPa}$ were $38.9,35.9$ and $32.8 \%$ respectively. These results indicate the increasing number of collisions between the emulsion droplets, which can break the film between the oil and water and cause many oil droplets to form a large droplet. As a result, a layer started to form above the membrane surface which may be compressed on the surface and throughout the pores at higher pressure [32]. The declines of the flux recovery ratio due to the emulsion oil had already blocked the pores and the fouling became more severe.

The effects of oil feed concentrations on the flux and recovery ratio are shown in Fig. 5(b). The results show that the steady state of permeation fluxes at $1500 \mathrm{ppm}$ is slightly lower than the other two concentration values. It

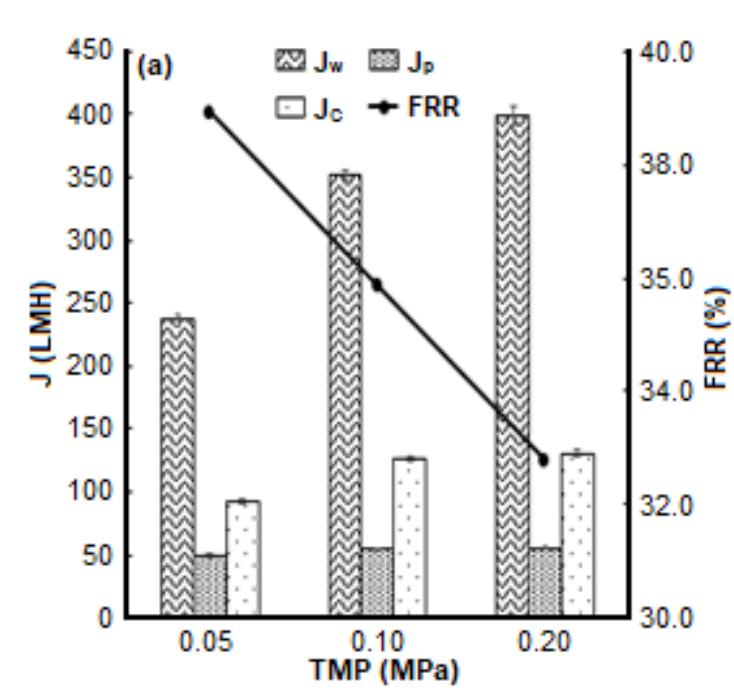

may be due to the increase of resistance to permeate flow, which is attributed to the formation of thicker oil layer on the membrane surface with oil of higher concentration. Thus, the oil droplets accumulate and build up a boundary layer on the membrane surface which may reduce the permeate flux. Again, as the oil concentration increases, the flux recovery ratio after the cleaning process decreases due to the extension of interactions between emulsion droplets and the membrane surface [33].

Fig. 6 shows the representation of experimental data for permeation flux of emulsion oil as feed solution at $0.05 \mathrm{MPa}$ with concentration of $500 \mathrm{ppm}$. The trends of permeate flux can be divided into three stages [34-35]. The rapid decline of flux in Stage I in the first 20 min was observed due to the build-up of oil layers on the membrane surface and within the pores. Then, the long gradual flux decline in Stage II for about 50 min was due to the accumulation of the retained oil droplets over the membrane surface. Stage III occurred after the cake layer build up on the membrane surface at maximum level and the steady state of flux was achieved until the end of the process.

In addition, the experimental filtration data of permeation flux of emulsion oil $\left(\mathrm{J}_{\mathrm{P}}\right)$ were fitted and analyzed using the blocking model to explain the fouling phenomenon of membrane processes during constant TMP. The calculated model constants $(\mathrm{K})$ and the values

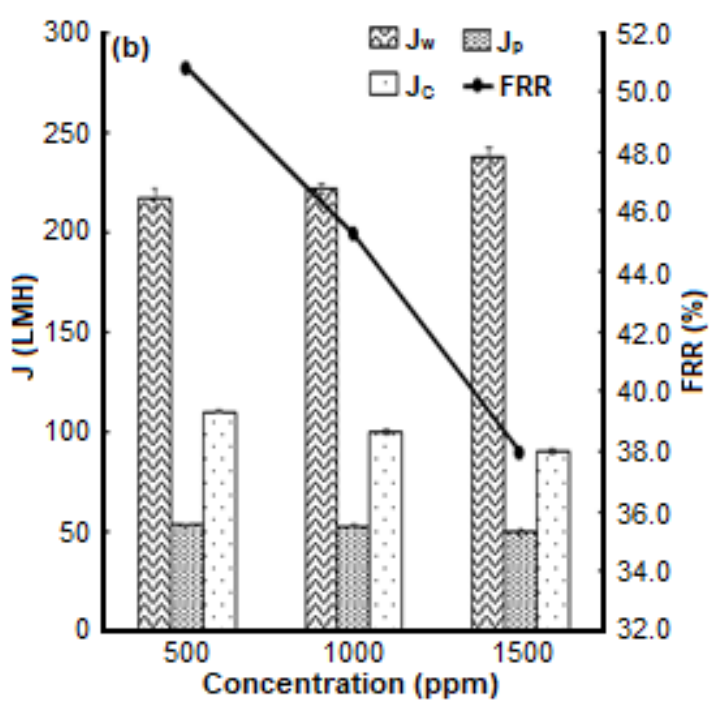

Fig 5. Permeation flux of emulsion oil and flux recovery at (a) different TMP and (b) different initial oil concentrations 
Table 2. Parameter of Hermia Model for permeate of emulsion oil feed solution

\begin{tabular}{cccccccccccc}
\hline \multicolumn{2}{c}{ Complete pore blocking } & \multicolumn{3}{c}{ Standard pore blocking } & \multicolumn{3}{c}{ Intermediate pore blocking } & \multicolumn{3}{c}{ Cake layer formation } \\
\hline $\mathrm{R}^{2}$ & $\mathrm{k}_{\mathrm{b}}$ & $\mathrm{J}_{0}$ & $\mathrm{R}^{2}$ & $\mathrm{k}_{\mathrm{s}}$ & $\mathrm{J}_{0}$ & $\mathrm{R}^{2}$ & $\mathrm{k}_{\mathrm{i}} \times 10^{-5}$ & $\mathrm{~J}_{0}$ & $\mathrm{R}^{2}$ & $\mathrm{k}_{\mathrm{c}} \times 10^{-6}$ & $\mathrm{~J}_{0}$ \\
\hline 0.8800 & 0.0061 & 89.7 & 0.9175 & 0.0004 & 90.4 & 0.9448 & 9.00 & 91.7 & 0.9739 & 3.00 & 100.0 \\
\hline
\end{tabular}

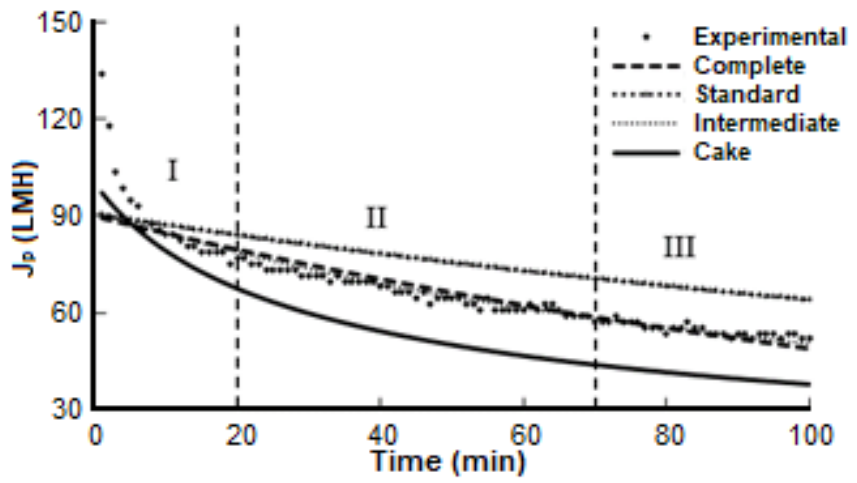

Fig 6. Permeation flux and model fitting of emulsion oil feed solution at $0.05 \mathrm{MPa}$

of coefficient of correlation $\left(\mathrm{R}^{2}\right)$ as shown in Table 2 were to determine whether the data agree with any of the considered models. The fitting of experimental permeate flux to the blocking models are illustrated in Fig. 6.

For all the models considered in this work, it can be concluded that the best of experimental data corresponds to the cake filtration model with $\mathrm{R}^{2}$ of 0.9739 followed by the intermediate pore blocking with the $\mathrm{R}^{2}$ value of 0.9448 . The difference between experimentally measured initial permeate flux and the initial permeate flux predicted by cake filtration model was approximately $25 \%$, while for the other three models it was above $32 \%$. Therefore, the evidence suggests that the cake filtration phenomenon is due to the much smaller membrane pore size compared to the size of emulsion oil droplets, which indicates that there is a uniform solute cake layer that forms over the entire membrane surface which exert resistance for fluid flow [32].

\section{- CONCLUSION}

In summary, facile modification of microfiltration PVDF membranes with high water permeation and separation performance using natural polyphenolic coating process was achieved. The inherent abundance of hydroxyl and amino groups induced by the coating process improved the membrane hydrophilicity. A significant enhancement of antifouling ability for emulsion oil separation was achieved due to the underwater oleophobic properties. Effect of transmembrane pressure and initial oil concentration had been investigated using cross-flow filtration. As expected, the results show that increasing the TMP increases permeation flux. However, it causes the reduction of flux recovery due to the compaction of cake layer formation thereby resulting in greater fouling. Also, the results on the higher oil concentration causes a decline in flux and flux recovery. The general blocking model has been evaluated at $0.05 \mathrm{MPa}$ with $500 \mathrm{ppm}$ of emulsified oil considering that the cake formation layer is the main fouling mechanism for the separations of emulsion oil.

\section{- ACKNOWLEDGMENTS}

The authors wish to thank the Ministry of Energy, Science, Technology, Environment and Climate Change Malaysia (MESTECC) (R\&D Fund Grant) (305/PJKIMIA/6013394) for the financial support throughout this study. Faraziehan Senusi gratefully acknowledges the generous financial support from the Ministry of Education Malaysia (Higher Education) and Universiti Teknologi MARA (UiTM) for her study leave.

\section{- REFERENCES}

[1] Zhu, Y., Wang, D., Jiang, L., and Jin, J., 2014, Recent progress in developing advanced membranes for emulsified oil/water separation, NPG Asia Mater., 6, e101.

[2] Genc, A., and Bakirci, B., 2015, Treatment of emulsified oils by electrocoagulation: Pulsed voltage applications, Water Sci. Technol., 71 (8), 1196-1202.

[3] Tripathi, B.P., Dubey, N.C., Subair, R., Choudhury, S., and Stamm, M., 2016, Enhanced hydrophilic and antifouling polyacrylonitrile membrane with 
polydopamine modified silica nanoparticles, RSC Adv., 6 (6), 4448-4457.

[4] Yin, J., Fan, H., and Zhou, J., 2016, Cellulose acetate/ poly(vinyl alcohol) and cellulose acetate/crosslinked poly(vinyl alcohol) blend membranes: preparation, characterization, and antifouling properties, Desalin. Water Treat., 57 (23), 10572-10584.

[5] Fang, L.F., Zhou, M.Y., Wang, N.C., Zhu, B.K., and Zhu, L.P., 2015, Improving the antifouling property of poly(vinyl chloride) membranes by poly(vinyl chloride)-g-poly(methacrylic acid) as the additive, $J$. Appl. Polym. Sci., 132 (44), 42745.

[6] Zhu, H., and Zhu, S., 2015, A versatile and facile surface modification route based on polydopamine for the growth of MOF films on different substrates, Can. J. Chem. Eng., 93 (1), 63-67.

[7] Bai, L., Liang, H., Crittenden, J., Qu, F., Ding, A., Ma, J., Du, X., Guo, S., and Li, G., 2015, Surface modification of UF membranes with functionalized MWCNTs to control membrane fouling by NOM fractions, J. Membr. Sci., 492, 400-411.

[8] Kwon, Y.N., Hong, S., Choi, H., and Tak, T., 2012, Surface modification of a polyamide reverse osmosis membrane for chlorine resistance improvement, $J$. Membr. Sci., 415-416, 192-198.

[9] Farahani, M.H.D.A., and Vatanpour, V., 2018, A comprehensive study on the performance and antifouling enhancement of the PVDF mixed matrix membranes by embedding different nanoparticulates: Clay, functionalized carbon nanotube, $\mathrm{SiO}_{2}$ and $\mathrm{TiO}_{2}$, Sep. Purif. Technol., 197, 372-381.

[10] Otitoju, T.A., Ahmad, A.L., and Ooi, B.S., 2016, Polyvinylidene fluoride (PVDF) membrane for oil rejection from oily wastewater: A performance review, J. Water Process Eng., 14, 41-59.

[11] Yu, S., Zhang, X., Li, F., and Zhao, X., 2018, Poly(vinyl pyrrolidone) modified poly(vinylidene fluoride) ultrafiltration membrane via a two-step surface grafting for radioactive wastewater treatment, Sep. Purif. Technol., 194, 404-409.

[12] Ding, Y.H., Floren, M., and Tan, W., 2016, Musselinspired polydopamine for bio-surface functionalization, Biosurf. Biotribol., 2 (4), 121-136.
[13] Sileika, T.S., Barrett, D.G., Zhang, R., Lau, K.H.A., and Messersmith, P.B., 2013, Colorless multifunctional coatings inspired by polyphenols found in tea, chocolate, and wine, Angew. Chem. Int. Ed., 52 (41), 10766-10770.

[14] Kang, S.M., Hwang, N.S., Yeom, J., Park, S.Y., Messersmith, P.B., Choi, I.S., Langer, R., Anderson, D.G., and Lee, H., 2012, One-step multipurpose surface functionalization by adhesive catecholamine, Adv. Funct. Mater., 22 (14), 2949-2955.

[15] Wei, Q., Zhang, F., Li, J., Li, B., and Zhao, C., 2010, Oxidant-induced dopamine polymerization for multi functional coatings, Polym. Chem., 1 (9), 1430-1433.

[16] Wang, J., Hou, L., Yan, K., Zhang, L., and Yu, Q.J., 2018, Polydopamine nanocluster decorated electrospun nanofibrous membrane for separation of oil/water emulsions, J. Membr. Sci., 547, 156-162.

[17] Kirschner, A.Y., Chang, C.C., Kasemset, S., Emrick, T., and Freeman, B.D., 2017, Fouling-resistant ultrafiltration membranes prepared via codeposition of dopamine/zwitterion composite coatings, J. Membr. Sci., 541, 300-311.

[18] Lee, H., Dellatore, S.M., Miller, W.M., and Messersmith, P.B., 2007, Mussel-inspired surface chemistry for multifunctional coatings, Science, 318 (5849), 426-430.

[19] Sousa, M.R.S., Lora-Garcia, J., and López-Pérez, M.F., 2018, Modelling approach to an ultrafiltration process for the removal of dissolved and colloidal substances from treated wastewater for reuse in recycled paper manufacturing, J. Water Process Eng., 21, 96-106.

[20] Vela, M.C.V., Blanco, S.Á., García, J.L., and Rodríguez, E.B., 2009, Analysis of membrane pore blocking models adapted to crossflow ultrafiltration in the ultrafiltration of PEG, Chem. Eng. J., 149 (13), 232-241.

[21] Chen, G.E., Sun, L., Xu, Z.L., Yang, H., Huang, H.H., and Liu, Y.J., 2015, Surface modification of poly(vinylidene fluoride) membrane with hydrophilic and anti-fouling performance via a two-step polymerizetion, Korean J. Chem. Eng., 32 (12), 2492-2500. 
[22] Zhao, X., and Liu, C., 2019, Efficient preparation of a novel PVDF antifouling membrane based on the solvent-responsive cleaning properties, Sep. Purif. Technol., 210, 100-106.

[23] Bittner, S., 2006, When quinones meet amino acids: Chemical, physical and biological consequences, Amino Acids, 30 (3), 205-224.

[24] Ding, L., Gao, J., and Chung, T.S., 2019, Schiff base reaction assisted one-step self-assembly method for efficient gravity-driven oil-water emulsion separation, Sep. Purif. Technol., 213, 437-446.

[25] Li, F., Ye, J., Yang, L., Deng, C., Tian, Q., and Yang, B., 2015, Surface modification of ultrafiltration membranes by grafting glycine-functionalized PVA based on polydopamine coatings, Appl. Surf. Sci., 345, 301-309.

[26] Qin, A., Li, X., Zhao, X., Liu, D., and He, C., 2015, Engineering a highly hydrophilic PVDF membrane via binding $\mathrm{TiO}_{2}$ nanoparticles and a PVA layer onto a membrane surface, ACS Appl. Mater. Interfaces, 7 (16), 8427-8436.

[27] Liu, C., Wu, L., Zhang, C., Chen, W., and Luo, S., 2018, Surface hydrophilic modification of PVDF membranes by trace amounts of tannin and polyethyleneimine, Appl. Surf. Sci., 457, 695-704.

[28] Sun, C., and Feng, X., 2017, Enhancing the performance of PVDF membranes by hydrophilic surface modification via amine treatment, Sep. Purif. Technol., 185, 94-102.

[29] Shi, H., Xue, L., Gao, A., Fu, Y., Zhou, Q., and Zhu, L., 2016, Fouling-resistant and adhesion-resistant surface modification of dual layer PVDF hollow fiber membrane by dopamine and quaternary polyethyleneimine, J. Membr. Sci., 498, 39-47.

[30] Chen, P.C., and Xu, Z.K., 2013, Mineral-coated polymer membranes with superhydrophilicity and underwater superoleophobicity for effective oil/water separation, Sci. Rep., 3, 2776.

[31] Xue, S., Li, C., Li, J., Zhu, H., and Guo, Y., 2017, A catechol-based biomimetic strategy combined with surface mineralization to enhance hydrophilicity and anti-fouling property of PTFE flat membrane, J. Membr. Sci., 524, 409-418.

[32] Vela, M.C.V, Blanco, S.Á., García, J.L., GozálvezZafrilla, J.M., and Rodríguez, E.B., 2007, Modelling of flux decline in crossflow ultrafiltration of macromolecules: Comparison between predicted and experimental results, Desalination, 204 (1-3), 328-334.

[33] Chakrabarty, B., Ghoshal, A. K., and Purkait, M. K., 2008, Ultrafiltration of stable oil-in-water emulsion by polysulfone membrane, J. Membr. Sci., 325 (1), 427-437.

[34] Song, L., 1998, Flux decline in crossflow microfiltration and ultrafiltration: mechanisms and modeling of membrane fouling, J. Membr. Sci., 139 (2), 183-200.

[35] Muhammad Sanusi, N.F.A., Mohd Yusoff, M.H., Seng, O.B., Marzuki, M.S., and Abdullah, A.Z., 2018, Ultrafiltration based on various polymeric membranes for recovery of spent tungsten slurry for reuse in chemical mechanical polishing process, J. Membr. Sci., 548, 232-238. 